\title{
Adsorptive characteristics of chromium (VI) ion from aqueous solutions using the modified crab shell
}

\author{
Hui Zhang, a , Cuizhen Sun ${ }^{2, \text { b }}$, Zhibin Zhang ${ }^{3, ~ c}$, Yang Zhao ${ }^{4, d}$ \\ 1,2,3,4 School of Municipal and Environmental Engineering, Shandong Jianzhu University, Ji'nan, \\ Shandong, 250100, China \\ asdjzuzhanghui@163.com, bsczh2901@126.com, 'zhibin_zhangsd@126.com, \\ dzhya1122@sina.com
}

Keywords: Adsorption; Waste crab shells; Chromium (VI); Mercaptoacetic acid.

Abstract. A novel biosorbent, waste crab shell modified with mercaptoacetic acid (WCS-SH), was prepared and used for the removal of chromium (VI) ion from aqueous solution. The effects of adsorbent dosages and contact time on chromium (VI) removal efficiency were investigated. Experimental results indicated that the chromium (VI) removal efficiency was improved in comparison with unmodified crab shell. It was noted that the adsorption of the Cr (VI) onto WCS-SH is largely influenced by the dosage of the adsorbent and the contact time.

\section{Introduction}

Nowadays, water pollution by heavy metals, such as $\mathrm{Ni}, \mathrm{Cd}, \mathrm{Hg}, \mathrm{Zn}, \mathrm{Cr}$ and $\mathrm{Pb}$, can cause serious environmental problem and generate a high toxicological risk to living organisms [1]. Chromium is one of the major toxic elements present in the environment and is widely used in chromate preparation, metal finishing, anodizing baths, leather tanning, and electroplating, etc [2-5]. Chromium mainly exists in the states of +3 and +6 in the aqueous solution. And, the two environmentally stable oxidation states, $\mathrm{Cr}$ (III) and $\mathrm{Cr}$ (VI), exhibit great difference in toxicity and mobility. $\mathrm{Cr}$ (III) is relatively insoluble in aqueous systems (above $\mathrm{pH}$ 5) and exhibits little or no toxicity. In contrast, hexavalent chromium exists in water as oxyanions such as chromate $\left(\mathrm{HCrO}_{4}{ }^{-}\right)$and dichromate $\left(\mathrm{Cr}_{2} \mathrm{O}_{7}{ }^{2-}\right)$ [6], which causes epigastric pain, nausea, vomiting, severe diarrhea, hemorrhaging and is suspected to be carcinogens and mutagens. Therefore, removal of chromium (VI) from water is significantly important from the environmental and health point of view.

There are various methods currently used for chromium removal from wastewater including chemical precipitation, ion exchange, electrodeposition and adsorption [7-12]. Among these methods, adsorption is considered to be one of the most promising techniques due to simplicity and flexibility in design and operation, and cost-effectiveness [13]. Therefore, it was pressing to develop a novel adsorbent to effectively remove chromium ions from wastewaters.

Containing high amounts of chitin or chitosan, waste crab shell (WCS) represents a potential bioadsorbent [14]. Due to low cost, rigid structure, excellent mechanical strength, and ability to withstand extreme conditions, such as high-temperature regeneration processes, the research on modified WCS was provided sufficient attention.

In this study, the adsorption of $\mathrm{Cr}^{6+}$ ions from aqueous solutions were investigated using mercaptoacetic acid modified waste crab shells (WCS-SH). The novel adsorbent was characterized and its adsorption performance was investigated for the removal of $\mathrm{Cr}^{6+}$ from water. The removal efficiency of the adsorbent was investigated as a function of contact time and adsorbent dosages.

\section{Materials and methods}

\section{Materials}

Raw WCS was obtained from a seafood market in Jinan, Shandong, China. All chemicals were purchased from China NationalMedicine Corporation Ltd. (Shanghai, China). All agents were analytical grade and all solutions were prepared with distilled water. 


\section{Preparation}

Firstly, WCS was washed by distilled water and dried. Then, it was crushed and sieved into 0.15 $\mathrm{mm}$ particles, which were soaked in $6 \% \mathrm{HCl}$. After $4 \mathrm{~h}$, the particles were washed with distilled water. The washed material was dried at 50ㄷ. WCS $(10 \mathrm{~g})$, mercaptoacetic acid $(150 \mathrm{~mL})$, glacial acetic acid $(150 \mathrm{~mL})$, acetylchloride $(30 \mathrm{~mL})$ and sulfuric acid $(3 \mathrm{~mL})$ were sequentially added into conical flask at room temperature, which then was shaken with bath shakers for $24 \mathrm{~h}$ at $120 \mathrm{rpm}$. Finally, the powder was washed with ditilled water was dried at $50^{\circ} \mathrm{C}$ to get WCS-SH.

$\mathrm{Cr}(\mathrm{VI})$ solutions were prepared with solid potassium dichromate and deionized water.

\section{Batch experiments for $\mathrm{Cr}(\mathrm{VI})$ adsorption}

Batch adsorption experiments were conducted by placing $0.2 \mathrm{~g}$ of adsorbent into $100 \mathrm{~mL}$ of $\mathrm{Cr}(\mathrm{VI})$ aqueous solutions $(2 \mathrm{mg} / \mathrm{L})$ in $250 \mathrm{~mL}$ conical flasks, being shaken with a mechanical rotary shaker at $180 \mathrm{rpm}$ for $24 \mathrm{~h}$. Then mixed solution was filtered through $0.45 \mu \mathrm{m}$ polytetrafluoroethylene membranes and the $\mathrm{Cr}(\mathrm{VI})$ concentrations in the filtrate was determined by atomic absorption spectrophotometer (Beijing Purkinje General Technologies, China). In the experiment of the adsorbent dosages effect, a series of WCS-SH/WCS $(0.01,0.02,0.04,0.08,0.10,0.20,0.40$ and $0.60 \mathrm{~g})$ were added to $100 \mathrm{~mL}$ of $\mathrm{Cr}(\mathrm{VI})$ solution $(2 \mathrm{mg} / \mathrm{L})$, respectively. To determine the influence of time on adsorptions, tests were conducted at different contact time values (4h, 8h, 12h, 24h, 48h and 72h). The adsorption capacities were calculated by the following expression:

$$
q_{e}=\frac{\left(C_{0}-C_{e}\right) V}{m}
$$

where $q_{e}$ is the adsorption amount of metal $(\mathrm{mg} / \mathrm{kg}) ; C_{0}$ and $C_{e}$ represented the initial and equilibrium concentrations of $\mathrm{Cr}(\mathrm{VI})$ in the solutions $(\mathrm{mg} / \mathrm{L})$, respectively; $V$ is the solution volume $(\mathrm{L})$; and $m$ is the biomass dose of WCS-SH (g).

The rate of removal was established by means of expression:

$$
R=\frac{C_{0}-C_{e}}{C_{0}} \times 100
$$

where $R$ is the equilibrium adsorption rate of the adsorbent, \%; $C_{0}$ and $C_{e}$ represented the initial and equilibrium concentrations of $\mathrm{Cr}(\mathrm{VI})$ in the solutions $(\mathrm{mg} / \mathrm{L})$, respectively.

\section{Results and discussion}

\section{Effect of WCS-SH dosage on the adsorption}

The influence of $\mathrm{Cr}(\mathrm{VI})$ ion sorption on dose was studied by varying the amount of WCS/WCS-SH adsorbents from 0.01 to $0.6 \mathrm{~g}$, while the volume $(100 \mathrm{~mL})$ and concentration $(2 \mathrm{mg} / \mathrm{L})$ of the solution constant were constant (temperature: $25^{\circ} \mathrm{C}$ ). From Fig. 1, it can be noted that removal efficiency increased greatly until the dose of the WCS-SH reached $0.04 \mathrm{mg}$. This was because of the fact that the exchange availability of the ions is higher at higher adsorbent dose. However, we found that the removal efficiency of $\mathrm{Cr}(\mathrm{VI})$ sharply decreased with the biomass dose increasing from 0.04 to $0.6 \mathrm{mg}$, which may be attributed to overlapping or aggregation of adsorbent surface area available for $\mathrm{Cr}(\mathrm{VI})$, and an increase in diffusion path length [15]. The amount of $\mathrm{Cr}(\mathrm{VI})$ adsorbed per unit mass of adsorbent decreased with increasing adsorbent dosage from 8.39 to $0.2 \mathrm{mg} / \mathrm{g}$. On the contrary, the removal percentage of $\mathrm{Cr}(\mathrm{VI})$ from solution increased continuously from $42.05 \%$ to $90.34 \%$ with increasing adsorbent dosages from 0.01 to $0.04 \mathrm{mg}$. 


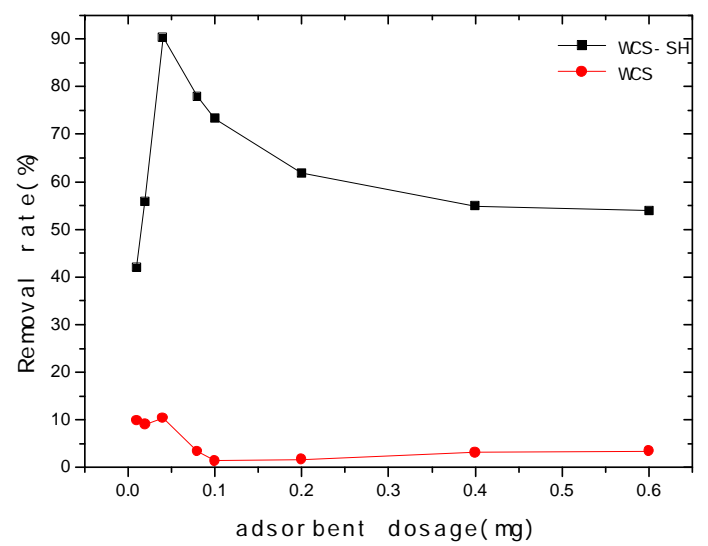

Fig. 1. The effect of adsorbent dosage on Cr(VI) adsorption onto WCS and WCS-SH at the initial $\mathrm{Cr}$ (VI) concentration of $2 \mathrm{mg} / \mathrm{L}$.

\section{Effect of contact time on the adsorption}

The effect of contact time on the removal of Cr(VI) from aqueous solution by WCS-SH was studied kinetically, and the results are presented in Fig. 2. As seen from Fig. 2, the adsorption kinetic study was investigated at temperature $25^{\circ} \mathrm{C}, 2 \mathrm{mg} / \mathrm{L} \mathrm{Cr}$ (VI) concentrations, $\mathrm{pH}$ 7. The removal efficiency of $\mathrm{Cr}$ (VI) ion increased sharply as the contact time increased from 0 to $12 \mathrm{~h}$, and then raised gently until it reached a plateau after $16 \mathrm{~h}$. The maximum adsorption capacity is $8.39 \mathrm{mg} / \mathrm{g}$ at the initial $\mathrm{Cr}$ (VI) concentration of $2 \mathrm{mg} / \mathrm{L}$. The removal efficiency for $\mathrm{Cr}(\mathrm{VI})$ ion was obviously fast at initial stage. A further increase in contact time has a negligible effect on the amount of adsorption. The main reason is that the bonding sites on the surface of adsorbent have greatly decreased [16].

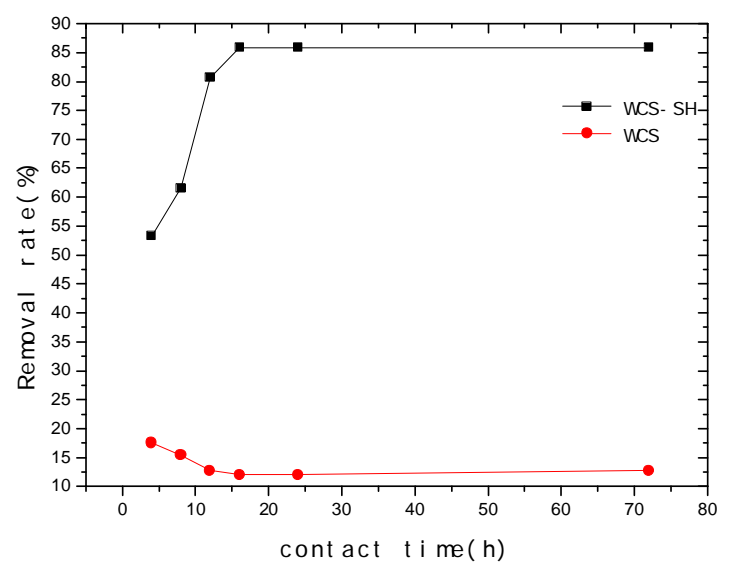

Fig. 2. The effect of contact time on Cr(VI) adsorption onto WCS and WCS-SH at the initial Cr (VI) concentration of $2 \mathrm{mg} / \mathrm{L}$.

In order to explain the adsorption potential and to make sure that the equilibrium is reached during adsorption, the contact time in subsequent batch experiments was fixed at $16 \mathrm{~h}$. The equilibrium time of $16 \mathrm{~h}$ can be considered very short. Relatively short equilibrium time coupled with high removals is considered as an important factor for a potential adsorbent.

\section{Conclusions}

The potential of waste crab shells modified with mercaptoacetic acid as adsorbent for $\mathrm{Cr}(\mathrm{VI})$ was investigated. The effects of adsorbent dosages and contact time on the adsorption of $\mathrm{Cr}(\mathrm{VI})$ by WCS-SH were further discussed. The maximum uptake of Cr(VI) using $0.04 \mathrm{mg}$ WCS-SH was 8.39 
$\mathrm{mg} / \mathrm{g}$. The adsorption was a fast process which could reach $85 \%$ of maximal uptake in $12 \mathrm{~h}$. The $\mathrm{Cr}(\mathrm{VI})$ uptake increased sharply as the contact time increased from 0 to $12 \mathrm{~h}$, and then raised gently until it reached a plateau after $16 \mathrm{~h}$. Thus the composite may be promising for application in the removal of $\mathrm{Cr}$ (VI) from the wastewater.

\section{Acknowledgements}

The authors are thankful to School of Municipal and Environmental Engineering, for providing necessary facilities required to carry out this work. The advice and kind suggestions from the anonymous reviewers are highly acknowledged.

\section{References}

[1]D.G. Liu, Z.H. Li, Y. Zhu, Z.X. Li, et al. Carbohydrate Polymers, Vol.111(2014),p.469-476.

[2] H.C. Ge, Z.W. Ma, Carbohydrate Polymers, Vol.131 (2015), p. 280-287.

[3] Bhattacharya, A. K., Naiya, et al. Chemical Engineering Journal, Vol.137(2008), p.529-541.

[4]Li, L. L., Fan, et al. Colloids and Surfaces B: Biointerfaces, Vol.107(2013), p.76-83.

[5] Ouaissa, Y. A., Chabani, M., et al. ChemicalEngineering \& Technology, Vol.36(2013), p.147-155.

[6]G.N. Kousalya, M.R. Gandhi, S. Meenakshi, Int. J. Biol. Macromol. Vol.47 (2010), p.308-315.

[7] Carlos, E. B. D., Violeta, et al. Journal of Hazardous Materials, Vol.1(2012), p. 223-224.

[8]X. J.Hu, J.S.Wang, Y. G.Liu, et al. Journal of Hazardous Materials, Vol.185(2011), p. 306-314.

[9] R.H. Huang, B.C. Yang, Q. Liu, Journal of Applied Polymer Science, Vol.129(2013), p.908-915.

[10] Gherasim, C. V., \& Bourceanu, G. Chemical Engineering Journal, Vol.220(2013), p.24-34.

[11] Golder, A.K., Samanta, et al. Chemical Engineering \& Technology, Vol.34(2011), p.775-783.

[12] Zhang Qiong, C. W., Wu, Ya, \& Li, Yu, Guangdong Chemical Industry, Vol. 41(2014), p.91-92.

[13] W. Wan Ngah, L. Teong, M. Hanafiah, Carbohydr. Polym. Vol. 83 (2011), p.1446-1456.

[14]Z.B. Zhang, X.R. Zhang, et al. Journal of Water Supply: Research and Technology, Vol.63(2014)

[15] Y.Zhu, H. Zhang, H. Zeng, M.Liang, Int. J. Environ. Sci. Technol. Vol.9 (2012), p.463-472.

[16] D.M. Chen, W. Li, Y.R. Wu, Q. Zhu, Z.J. Lu, G.X. Du, Chem. Eng. Vol.221 (2013), p.8-15. 